This article can be cited before page numbers have been issued, to do this please use: C. Molina, A. Ortega-Martínez, J. Sansano and C. Najera, Org. Biomol. Chem., 2018, DOI: 10.1039/C8OB01811A.

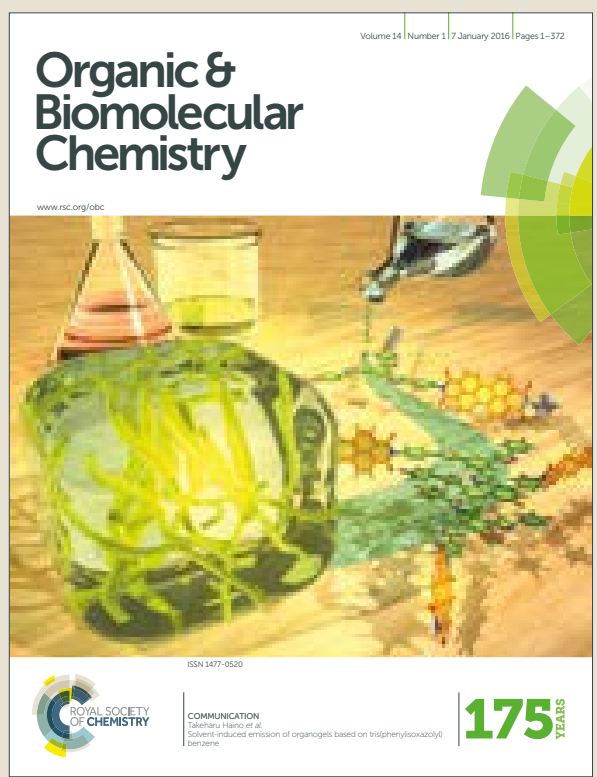

This is an Accepted Manuscript, which has been through the Royal Society of Chemistry peer review process and has been accepted for publication.

Accepted Manuscripts are published online shortly after acceptance, before technical editing, formatting and proof reading. Using this free service, authors can make their results available to the community, in citable form, before we publish the edited article. We will replace this Accepted Manuscript with the edited and formatted Advance Article as soon as it is available.

You can find more information about Accepted Manuscripts in the author guidelines.

Please note that technical editing may introduce minor changes to the text and/or graphics, which may alter content. The journal's standard Terms \& Conditions and the ethical guidelines, outlined in our author and reviewer resource centre, still apply. In no event shall the Royal Society of Chemistry be held responsible for any errors or omissions in this Accepted Manuscript or any consequences arising from the use of any information it contains. 


\section{Synthesis of 3-Substituted 3-Fluoro-2-Oxindoles by Deacylative Alkylation}

Received 00th January 20xx, Accepted 00th January 20xx

DOI: $10.1039 / \times 0 \times x 00000 x$

www.rsc.org/

\begin{abstract}
Cynthia Molina, ${ }^{a, b}$ Aitor Ortega-Martínez, ${ }^{a, b}$ José M. Sansano, ${ }^{* a, b}$ and Carmen Nájera*a
\end{abstract}
Abstract : The fluorination of 3-acetyl-2-oxindoles with $\mathrm{N}$-fluorobenzenesulfonimide under Lewis acid catalysis using $\mathrm{Mg}\left(\mathrm{ClO}_{4}\right)_{2}$ gives the starting compounds 3-acetyl-3-fluoro-2-oxindoles. These compounds are submitted to base-promoted deacylative alkylation ( $\mathrm{DaA})$ for the in situ generation of 3-fluoro-2-oxindole enolates under very mild reaction conditions using Triton B (1 equiv) and alkyl halides and Michael acceptors as electrophilic reagents. The corresponding 3-alkylated-3fluoro-2-oxindoles are obtained in good to very high yields. In addition, the palladium-catalyzed deacylative allylation is carried out with allylic alcohols using LiOtBu as base and $6 \mathrm{~mol} \%$ of $\mathrm{Pd}(\mathrm{OAc})_{2}$ and dppp, giving the resulting 3-allylated 3fluoro-2-oxindoles in good yields. This methodology allows a simple synthesis 3-alkylated-3-fluoro-2-oxindoles, which are difficult to obtain by other routes.

\section{Introduction}

Disubstituted 2-oxindoles at the 3-position are present in many natural products ${ }^{1}$ and pharmaceuticals. ${ }^{2}$ The introduction of a fluorine atom at the 3-position of the oxindole ring enhances its biological activity as is the case in many drugs. A representative example is BMS 204352 (MaxiPost) a calcium sensitive opener of maxi-K channels for the treatment ischemia stroke (Chart 1$).^{3}$<smiles>COc1ccc(Cl)cc1C1(F)C(=O)Nc2cc(C(F)(F)F)ccc21</smiles>

BMS 204352 (MaxiPost)

Chart 1. Structure of MaxiPost.

Generally, 3-substituted 3-fluoro-2-oxindoles are prepared by deprotonation of oxindole with sodium hydride followed by fluorination with $\mathrm{N}$-fluorobenzenesulfonimide (NFSI) of 3 substituted oxindoles ${ }^{4}$ and by fluorination of 3-substituted 3hydroxy-2-oxindoles with diethylaminosulfur trifluoride (DAST)
(Scheme 1, eq a). ${ }^{3 a}$ In the first case, a ca. 4:1 mixture of monofluorinated and difluorinated oxindoles are obtained. ${ }^{5}$ These monofluorinated oxindoles have been used as nucleophiles in different nucleophilic additions and in allylic substitutions. The most important applications of these fluorinated systems is summarized in Scheme $1 \mathrm{~b}-\mathrm{d}$ ). An asymmetric methodology was designed from 3-fluorooxindoles, which were allowed to react with Michael acceptors in the presence of an amine or a phosphine as organocatalysts (Scheme 1, eq b). ${ }^{5}$ Recently, the Tsuji-Trost asymmetric allylic alkylation of 3-fluorooxindoles with allylic acetates has been also applied to the synthesis of 3-substituted 3-fluoro-2oxindoles (Scheme 1, eq c). ${ }^{6}$ Detrifluoroacetylative alkylations have been described by Colby et al. ${ }^{7}$ and extensively applied by Soloshonok et $a .^{8}$ to the generation of fluoroenolates. In the case of the base-promoted detrifluoroacetylative alkylation reaction, affording 3-fluoro-2-oxindole enolates, it has been used for the diastereoselective Mannich reaction with chiral $\mathrm{N}$ tert-butanesulfinyl imines ${ }^{9}$ and for the $\mathrm{S}_{\mathrm{N}} 2^{\prime}$ allylation with Morita-Baylis-Hillman carbonates ${ }^{10}$ (Scheme 1 , eq d).

\footnotetext{
a. Department of Organic Chemistry and Centro de Innovación en Química Avanzada (ORFEO-CINQA). Faculty of Sciences, University of Alicante, E-03080 Alicante, Spain. Fax: +34965903549

b. Instituto de Síntesis Orgánica, University of Alicante.
}

Electronic Supplementary Information (ESI) available: [details of any supplementary information available should be included here]. See DOI: 10.1039/x0xx00000x 


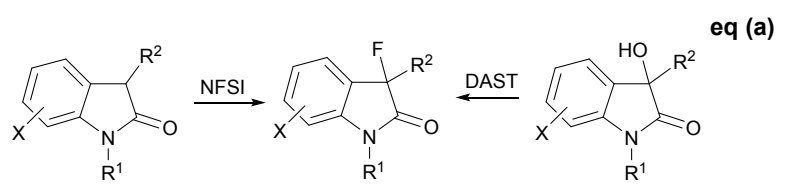

eq (b)

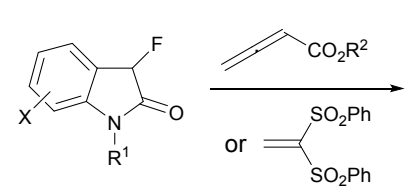<smiles>[X]c1ccccc1C1(F)C(=O)N([R])c2ccccc2C1(F)CC(Oc1ccccc1)C(=O)O</smiles><smiles>[R]C=CC([R])OC([R])C([R])C1(F)C(=O)N([R1])c2[Y](C)cccc21</smiles>

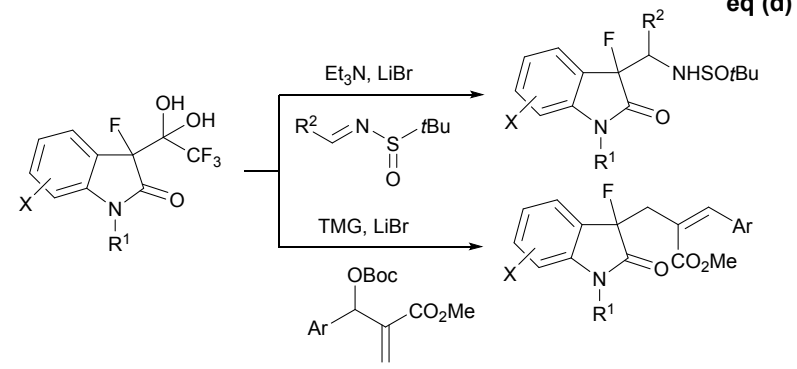

Deacylative alkylations $(\mathrm{DaA})^{11}$ of carbon nucleophiles have been recently implemented as a mild strategy for the generation of quaternary stereocenters. The acetyl or trifluoroacetyl group can be easily introduced at the $\alpha$-position of the carbon nucleophile by Claisen condensation with acetic anhydride of ethyl trifluoroacetate, respectively (Scheme 2, eq a). These acylated carbon nucleophiles can easily generated the enolate in the presence of the electrophile by a retro-Claisen condensation promoted by a base (Scheme 2, eq b and c). This methodology has been carried out under Pd-catalysis with allylic alcohols ${ }^{12}$ (Scheme 2, eq b) or even mediated by a base ${ }^{7-}$ ${ }^{10}$ (Scheme 2, eq c).

Our group has described the base-mediated alkylation of 3acetyl-2-oxindoles with alkyl halides and electrophilic olefins, ${ }^{13}$ and the Pd-catalyzed allylation with allylic alcohols. ${ }^{14}$ We envisaged that 3-acetyl-3-fluoro-2-oxindole can be easily generated by fluorination of 3-acetyl-2-oxindole and applied to the synthesis of 3-substituted 3-fluoro-2-oxindoles by basepromoted and Palladium-catalyzed DaA.

Scheme 1. Synthesis and reactivity of 3-substituted 3-fluoro-2oxindoles.
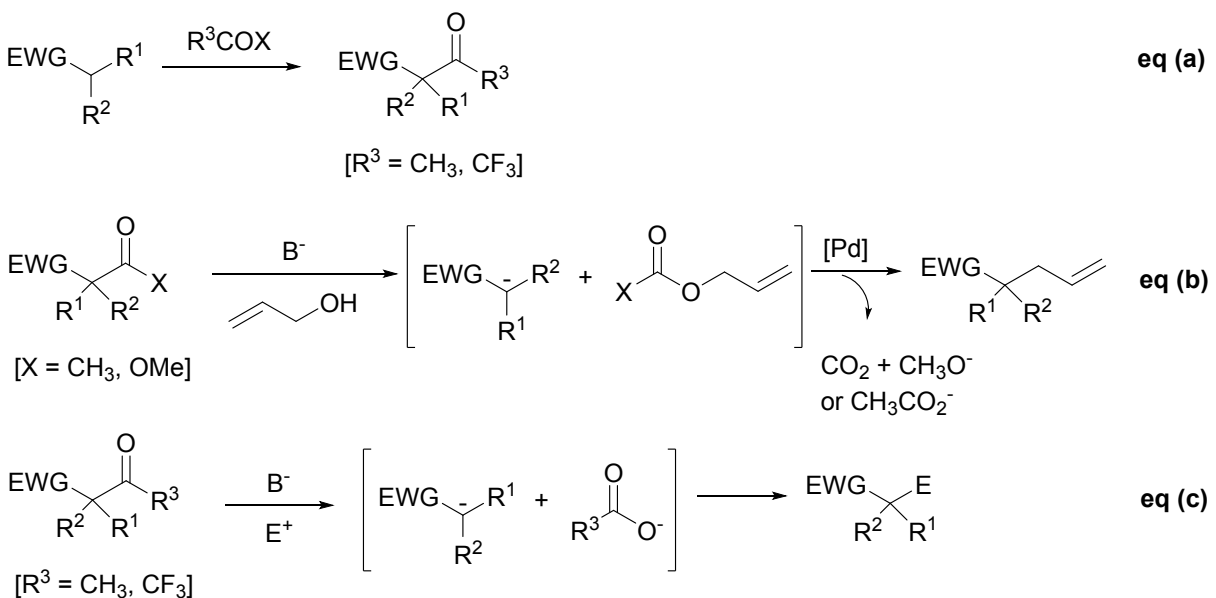

Scheme 2. Claisen condensation and deacylative alkylation of carbon nucleophiles. 


\section{Results and discussion}

The synthesis of the starting 3-acetyl-3-fluoro-1-methyl-2oxindole (2a) was carried out by fluorination of the corresponding 3-acetyl-1-methyl-2-oxindole (1a) ${ }^{13}$ with NFSI. This fluorination was firstly attempted under basic conditions, using benzyltrimethylammonium hydroxide (Triton B) (40\% wt in $\mathrm{MeOH}$ ) in THF at rt. Compound 2a, as well as 3-fluoro-1methyl-2-oxindole, and 3,3-difluoro-1-methyl-2-oxindole were obtained in $80 \%$ overall yield. Under Brønsted acid catalysis using 15 mol\% of $p$-toluenesulfonic acid in THF at rt during $2 \mathrm{~d}$, product 2 a was isolated in $85 \%$ yield. However, this method could not be scaled up. Under Lewis acid catalysis using $30 \mathrm{~mol} \%$ of $\mathrm{Mg}\left(\mathrm{ClO}_{4}\right)_{2}{ }_{2}^{15}$ in EtOAc at rt overnight, product $2 \mathrm{a}$ was isolated in $89 \%$ yield and could be scale up at least to $8 \mathrm{mmol}$ (Scheme 3). These last optimized conditions served to prepare compounds $\mathbf{2 b}-\mathbf{d}$ in high yields (Scheme 3). ${ }^{13}$ During the purification of starting materials $\mathbf{2} \mathbf{b}$ and $\mathbf{2} \mathbf{d}$ the corresponding fluorinated deacylated compounds was formed in $13 \%$ and $9 \%$, respectively.

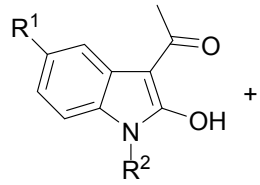

1a, $\mathrm{R}^{1}=\mathrm{H}, \mathrm{R}^{2}=\mathrm{Me}$

1b, $\mathrm{R}^{1}=\mathrm{MeO}, \mathrm{R}^{2}=\mathrm{Me}$

1c, $\mathrm{R}^{1}=\mathrm{Cl}, \mathrm{R}^{2}=\mathrm{Me}$

1d, $\mathrm{R}^{1}=\mathrm{MeO}, \mathrm{R}^{2}=\mathrm{Bn}$

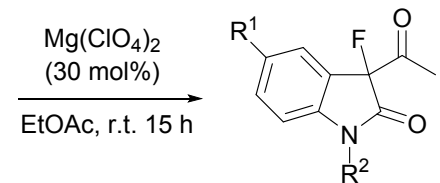

2a, $89 \%$

2b, $74 \%$

2c, $66 \%$

2d, $73 \%$
Scheme 3 Synthesis of 3-acetyl-3-fluoro-1-methyl-2-oxindoles 2.

When the fluorination of $N$-methyl-2-oxindole was performed with 1 equiv of NFSI using Triton B as base in THF at $\mathrm{rt}$, a 1:2 mixture of the desired monofluorinated oxindole $\mathbf{3 a}$ and difluorinated oxindole was obtained in $47 \%$ overall yield. So, we considered interesting to generate monofluorinated compound $\mathbf{3}$ from acetylated fluoroxindole $\mathbf{2 a}$. For this purpose, and with the idea to prevent the oxidation at 3-position, the reaction mixture was degassed prior to the addition of one equivalent of Triton B. ${ }^{13}$ The reaction is very fast ( $5 \mathrm{~min}$ ) and the final product could be purified and isolated in $50-59 \%$ yield (Scheme 4). The chemical yields of compounds $\mathbf{3}$ are not very high due to a partial decomposition detected after flash chromatography.
View Article Online DOI: $10.1039 /$ C8OB01811A

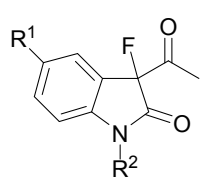

2a, $\mathrm{R}^{1}=\mathrm{H}, \mathrm{R}^{2}=\mathrm{Me}$

2b, $\mathrm{R}^{1}=\mathrm{OMe}, \mathrm{R}^{2}=\mathrm{Me}$

2c, $\mathrm{R}^{1}=\mathrm{Cl}, \mathrm{R}^{2}=\mathrm{Me}$

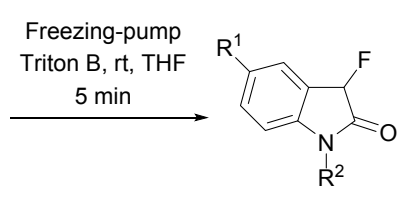

3<smiles>COc1ccc2c(c1)C(F)C(=O)N2C</smiles>

Scheme 4 Synthesis of fluoro-1-methyl-2-oxindole 3.

For the base-promoted deacylative alkylation of compounds 2, the same bases used for the deacylative alkylation of 3-alkyl3-acetyl-2-oxindoles, ${ }^{13}$ LiOEt and Triton B were assayed. The best results were obtained with 1 equiv of Triton $\mathrm{B}$ in $\mathrm{MeOH}$ $(40 \% \mathrm{wt})$ for both, alkyl halides and electrophilic alkenes (Table 1). In the case of the alkylation with non-activated methyl iodide, compound 4 a was obtained in $71 \%$ yield (Table 1 , entry 1). The reaction with different allyl bromides took place in higher yields through a $\mathrm{S}_{\mathrm{N}} 2$ mechanism giving products $\mathbf{4 b}-\mathbf{4} \mathbf{f}$ in good yields (Table 1 , entries 2-6). When 3-bromocyclohexenyl was used as electrophile a ca. 1:1 mixture of diastereomers $4 e$ were formed (Table 1, entry 5). DaA with benzyl bromides gave products $\mathbf{4 g}$ and $\mathbf{4 h}$ in high yields (Table 1 , entries 7 and 8). Propargyl bromide reacted with compound 2 a giving the propargyl derivative $\mathbf{4} \mathbf{i}$ in moderate $59 \%$ yield (Table 1 , entry 9 ). The alkylation with ethyl 2-(bromomethyl)acrylate provided product $4 \mathbf{j}$ in $82 \%$ yield (Table 1 , entry 10 ). The presence of different substituents of the indole moiety did not affect the reaction course. Thus, starting compounds $\mathbf{2 b}-\mathbf{d}$ reacted in the presence of benzyl bromide to give disubstituted oxindole derivatives $\mathbf{4 k}, \mathbf{l}, \mathbf{m}$, respectively, in good yields (Table 1 , entries 11-13).

When electrophilic olefins were used as Michael acceptors the reaction was performed using freezing pump giving the corresponding compounds 5 in good yields (Table 1, entries 1423). The reaction with tert-butyl acrylate, acrylonitrile and $N, N$ dimethylacrylamide afforded products $\mathbf{5 a - 5 c}$ in 75 to $95 \%$ yield (Table 1, entries 14-16). Methyl vinyl ketone, (phenylsulfonyl)ethylene and diethyl vinylphosphonate provided products $\mathbf{5 d - 5 f}$ in $\mathbf{7 0 \%}$ yield (Table 1, entries 17-19). Excellent $92 \%$ yield was achieved in the case of 1,1bis(phenylsulfonyl)ethylene giving the corresponding adduct $\mathbf{5 g}$ (Table 1, entry 20). Again, starting compounds 2b-d satisfactorily reacted with tert-butyl acrylate to give disubstituted oxindole derivatives $\mathbf{5 h}, \mathbf{i}, \mathbf{j}$, respectively, in good yields (Table 1, entries 21-23). 
Table 1. Base-promoted DaA of 3-acetyl-3-fluoro-1-methyl-2-

10

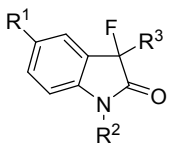

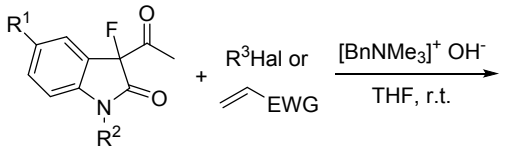

2a, $R^{1}=H, R^{2}=M e, 89 \%$

2b, $\mathrm{R}^{1}=\mathrm{MeO}, \mathrm{R}^{2}=\mathrm{Me}, 74 \%$

2c, $\mathrm{R}^{1}=\mathrm{Cl}, \mathrm{R}^{2}=\mathrm{Me}, 66 \%$

2d, $R^{1}=\mathrm{MeO}, \mathrm{R}^{2}=\mathrm{Bn}, 73 \%$

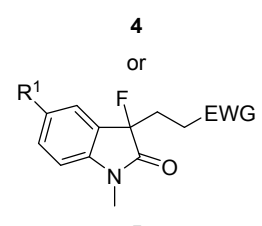

5

Entry Electrophile

No. Product

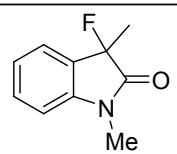

71

$2 \quad \mathrm{CH}_{2}=\mathrm{CHCH}_{2} \mathrm{Br}$

4b<smiles>C=CCC1(F)C(=O)N(C)c2ccccc21</smiles>

Yield

$(\%)^{b}$

14

11

$\mathrm{PhCH}_{2} \mathrm{Br}$

12

$\mathrm{PhCH}_{2} \mathrm{Br}$

13

$\mathrm{PhCH}_{2} \mathrm{Br}$

$\int_{\mathrm{CO}_{2} \mathrm{Et}}^{\mathrm{Br}}$

$4 \mathbf{j}$

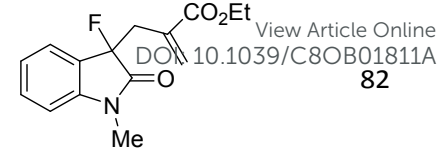

$4 \mathbf{k}$<smiles>COc1ccc2c(c1)C(F)(Cc1ccccc1)C(=O)N2C</smiles>

41

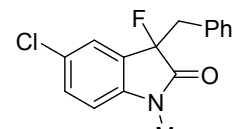

77

$4 \mathrm{~m}$

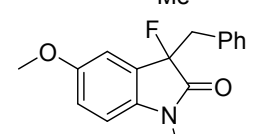

76

$\mathrm{Bn}$<smiles>CCCCCC1(F)C(=O)N([N+](=O)[O-])c2ccccc21</smiles>

95

$15^{e} \quad \mathrm{CH}_{2}=\mathrm{CHCN}$

91

$78^{c}$

75

$17^{e} \quad \mathrm{CH}_{2}=\mathrm{CHCOMe}^{f}$

5d<smiles>[Y6]N1C(=O)C(F)(CCC#N)c2ccccc21</smiles>

75

81

70

$84^{d}$

$18^{e} \quad \mathrm{CH}_{2}=\mathrm{CHSO}_{2} \mathrm{Ph}$

$5 e$<smiles>CC(=O)CCC1(F)C(=O)N(C(C)(C)C)c2ccccc21</smiles>

$4 e$<smiles>CN1C(=O)C(F)(C2C=CCCC2)c2ccccc21</smiles>

(E)-

$\mathrm{PhCH}=\mathrm{CHCH}_{2} \mathrm{Br}$

$4 f$<smiles>O=C([O-])N1C(=O)C(F)(C/C=C/c2ccccc2)c2ccccc21</smiles>

85

$19^{e} \quad \mathrm{CH}_{2}=\mathrm{CHPO}(\mathrm{OEt})_{2}$<smiles>CC(=O)CCC1(F)C(=O)N(c2ccccc2S(C)(=O)=O)c2ccccc21</smiles><smiles>CN1C(=O)C(F)(CCS(=O)(=O)c2ccccc2)c2ccccc21</smiles>

69

92

92

$21 \quad \mathrm{CH}_{2}=\mathrm{CHCO}_{2} t \mathrm{Bu}$

$5 \mathrm{~h}$<smiles>CCOPCCC1(F)C(=O)N([N+](=O)[O-])c2ccccc21</smiles>

86

$22 \mathrm{CH}_{2}=\mathrm{CHCO}_{2} \mathrm{tBu}$

$5 i$

$20^{e} \quad \mathrm{CH}_{2}=\mathrm{C}\left(\mathrm{SO}_{2} \mathrm{Ph}\right)_{2}^{f} \quad 5$<smiles></smiles><smiles>[Y6]N1C(=O)C(F)(CCCCC)c2cc(OC)ccc21</smiles>

\section{2

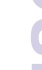

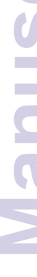

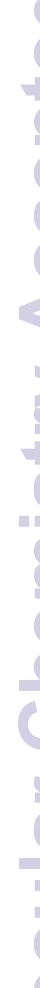<smiles>CCCCC1(F)C(=O)N([N+](=O)[O-])c2ccc(Cl)cc21</smiles> 


$$
23 \quad \mathrm{CH}_{2}=\mathrm{CHCO}_{2} \mathrm{tBu} \quad 5 \mathbf{5}
$$

${ }^{a}$ Reaction conditions: $2(0.3 \mathrm{mmol})$, electrophile $(0.42 \mathrm{mmol})$, Triton $\mathrm{B}$ $(0.3 \mathrm{mmol})$, THF $(3 \mathrm{~mL}), 17 \mathrm{~h}$ at rt under argon atmosphere. ${ }^{b}$ Isolated yields after flash chromatography. ${ }^{c} \mathrm{~A}$ ca. 1:1 mixture of diastereomers. ${ }^{c}$ 85:15 Mixture of Z/E diastereomers. ${ }^{e}$ Using freezing-pump. ${ }^{f} 1$ equiv was used. ${ }^{g}$ This product decomposed on the column and was purified washing the solid with tert-butyl methyl ether.

Next, the palladium-catalyzed deacylative allylation of compound $\mathbf{2}$ with allylic alcohols was studied (Table 2). In this case, the reaction conditions were slightly modified with respect to the previous ones described for 3-alkyl-3acetyloxindoles. ${ }^{14}$ The amount of $\mathrm{Pd}(\mathrm{OAc})_{2}$ and 1,3bis(diphenylphosphino)propane (dppp) was increased from 3 to $6 \mathrm{~mol} \%$ and the best solvent was toluene instead of THF. As base litium tert-butoxide was the best and the reaction was also carried out at rt. When allyl alcohol and $\mathbf{2 a}$ were used, product $\mathbf{4 b}$ was obtained in $85 \%$ yield (Table 2 , entry 1 ). However, in the case of crotyl alcohol a 1:1 mixture of regioisomeric compounds $\mathbf{4 c}$ and $\mathbf{4} \mathbf{c}^{\prime}$ was isolated in $55 \%$ overall yield (Table 2 , entry 2 ). When cyclohexen-3-ol was assayed the corresponding 1:1 mixture of diastereomers $\mathbf{4 e}$ were formed (Table 2, entry 3 ) as in the case of the DaA with 3-bromocyclohexene (Table 1, entry 5 ) but in lower $61 \%$ yield. The same product $4 \mathbf{j}$ was prepared using ethyl 2-(hydroxymethy)acrylate although in lower $57 \%$ yield (compare Table 1, entry 10 with Table 2, entry 4). Methallyl alcohol and $(E)$-hexen-2-ol gave products $4 \mathrm{n}$ and $4 \mathrm{o}$ in $82 \%$ and $60 \%$ yield, respectively (Table 2 , entries 5 and 6 ). When penta-1,4-dien-3-ol was allowed to react with compound 2, a 2:1 mixture of regiosomeric products $4 p$ and $\mathbf{4 p}$ ' were formed in $60 \%$, compound $4 p$ being obtained with $E$-configuration yield (Table 2, entry 7). The observed gap in the chemical yields between $\mathbf{4 b}$ or $\mathbf{4 n}$ with respect to the other products can be produced by the steric hinderance of the allyl system. In addition, this palladium-promoted allylation was not sensitive to the presence of substituent of the raw materials 2 . For example, products $\mathbf{4 q - \mathbf { s }}$ were isolated in $81-64 \%$ yields when allyl alcohol was used (Table 2, entries 8-10).

Table 2. Palladium-catalyzed DaA of 3-acetyl-3-fluoro-1-methyl2-oxindoles $2 .^{a}$

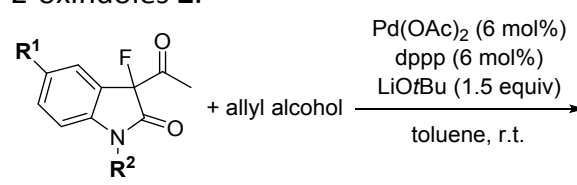

2a, $R^{1}=H, R^{2}=M e$ 2b, $R^{1}=O M e, R^{2}=M e$

2c, $\mathrm{R}^{1}=\mathrm{Cl}, \mathrm{R}^{2}=\mathrm{Me}$

2d, $R^{1}=O M e, R^{2}=B n$

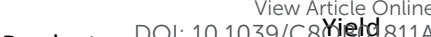 \\ No. Product DOI: $10.1039 / \mathrm{C} 8 \mathrm{Cietd} / \mathrm{d}$
$(\%)^{b}$}

(1)

a Reaction conditions: 2 (0.3 mmol), allyl alcohol $(0.45 \mathrm{mmol})$, LitBuO (0.45 mmol), Pd(OAc) 2 (6 mol\%), dppp (6 mol\%), toluene (1.5 $\mathrm{mL}), 17 \mathrm{~h}$ at $\mathrm{rt}$ under argon atmosphere and using freezing-pump. ${ }^{b}$ Isolated yields after flash chromatography. ${ }^{c}$ A ca. 1:1 mixture of regioisomers. ${ }^{d} A$ 1:1 mixture of diasteromers. ${ }^{e}$ A 2:1 mixture of $4 p$ and $4 p^{\prime}$ was obtained. 
At this moment, all these families of fluorinated compounds are being testing as antibacterial and anticancer agents by Lilly Spain.

\section{Conclusions}

The deacylative alkylation of 3-acetyl-3-fluoro-1-alkyl-2oxindoles is a new strategy for the synthesis of 3-alkylated 3fluoro-2-oxindoles under very mild reaction conditions. This process can be performed with Triton B as base using alkyl halides and electrophilic alkenes as alkylation reagents. Not easily available 3 -fluorooxindoles could also be obtained by direct deacetylation using analogous reaction conditions. In the case of using allylic alcohols, the Pd-catalyzed deacylative allylation can be used at $\mathrm{rt}$ in the presence of LitBuO as base also at room temperature. The DaA with allyl bromides gave in general higher yields than the Pd-catalyzed allylation of the corresponding fluorinated oxindoles.

\section{Experimental}

Synthetic procedures and characterization of the products including NMR spectra are available in ESI.

\section{Conflicts of interest}

There are no conflicts to declare.

\section{Acknowledgements}

We gratefully acknowledge financial support from the Spanish Ministerio de Economía y Competitividad (MINECO) (projects CTQ2013-43446-P and CTQ2014-51912-REDC), the Spanish Ministerio de Economía, Industria y Competitividad, Agencia Estatal de Investigación (AEI) and Fondo Europeo de Desarrollo Regional (FEDER, EU) (projects CTQ2016-76782-P and CTQ2016-81797-REDC), the Generalitat Valenciana (PROMETEOII/2014/017) and the University of Alicante. A. O.-M. thanks MINECO for a predoctoral fellowship.

\section{Notes and references}

1 For recent reviews, see: (a) Z.-Y. Cao, Y.-H. Wang, Y.-P. Zeng, J. Zhou, Tetrahedron Lett. 2014, 55, 2571; (b) G. S. Singh, Z. Y. Desta, Chem. Rev. 2012, 112, 6104; (c) R. Dalpozzo, G. Bartoli, G. Bencivenni, Chem. Soc. Rev. 2012, 41, 7247; (d) K. Shen, X. Liu, X. Feng, Chem. Sci. 2012, 3, 327; (e) F. Zhou, Y.-L. Liu, J. Zhou, Adv. Synth. Catal. 2010, 352, 1381; (f) C. V. Galliford, K. A. Scheidt, Angew. Chem., Int. Ed. 2007, 46, 8748.

2 (a) B. Volk, J. Barkóczy, E. Hegedus, S. Udvari, I. Gassályi, T. Mezu, K. Pallagi, H. Kompahne, G. Lévay, A. Egyed, J. L. G. Hársing, M. Spedding, G. Simig, J. Med. Chem. 2008, 51, 2522; (b) A. Fensome, W. R. Adams, A. L. Adams, T. J. Berrodin, J. Cohen, C.
Huselton, A. Illenberger, J. C. Kern, V. A. Hudack, MenAtrMarella, E. G. Melenski, C. C. McComas, C. A. Mugford,00 D?/Slaydeh, NA. Yudt, Z. Zhang, P. Zhang, Y. Ahu, R. C. Winnecker, J. E. Wrobel, J. Med. Chem. 2008, 51, 1861; (c) F. C. Stevens, W. E. Bloomquist, A. G. Barel, M. L. Cohen, C. A. Droste, M. L. Heiman, A. Kriauciunas, D. J. Sall, F. C. Tinsley, C. D. Jesudason, Bioorg. Med. Chem. 2007, 17, 6270; (d) T. Jiang, K. L. Kuhen, K. Wolff, H. Yin, K. Bieza, J. Caldwell, B. Bursulaya, T. Y.-H. Wu, Y. Ye, Bioorg. Med. Chem. Lett. 2006, 16, 2105; (e) A. Denis, F. Bretin, C. Fromentin, A. Bonnet, A. Bonmfoy, C. Agouridas, G. Piltan, Bioorg. Med. Chem. Lett. 2000, 10, 2019.

3 (a) P. Hewawasam, V. K. Gribkoff, Y. Pendri, S. I. Dworetzky, N. A. Meanwell, E. Martínez, C. G. Boissard, D. J. Post-Munson, J. T. Trojnacki, K. Yeleswaram, L. M. Pajor, J. Knipe, Q. Gao, R. Perrone, J. E. Starrett, Bioorg. Med. Chem. Lett. 2002, 12, 1023; (b) V. K. Gribkoff, J. E. Startett, S. I. Dworetzky, P. Hewawasam, C. G. Boissard, D. A. Cook, S. W. Frantz, K. Heman, J. R. Hibbard, K. Huston, G. Johnson, B. S. Krishman, G. G. Kinney, L. A. Lombardo, N. A. Meanwell, P. B. Molinoff, R. A. Myers, S. L. Moon, A. Ortiz, L. Pajor, R. L. Pieschl, D. J. Post-Munson, L. J. Signor, N. Srinivas, M. T. Taber, G. Thalody, J. T. Trojnacki, H. Wiener, K. Yeleswaram, S. W. Yeola, Nat. Med. 2001, 7, 471.

4 (a) Y. Hamashima, T. Suzuki, M. Takano, Y. Shimura, M. Sodeoka, J. Am. Chem. Soc. 2005, 127, 10164; (b) N. Shibata, J. Kohno, K. Takai, T. Ishimaru, S. Nakamura, T. Toru, S. Kanemasa, Angew. Chem., Int. Ed. 2005, 44, 4204-4207; (c) T. Ishimaru, N. Shibata, T. Horikawa, N. Yasuda, S. Nakamura, T. Toru, M. Shiro, Angew. Chem., Int. Ed. 2008, 47, 4257; (d) Q.-H. Deng, H. Wadepohl, L. H. Gade, Chem. Eur. J. 2011, 17, 14922; (e) K. Shen, X. H. Liu, L. L. Lin, X. M. Feng, Chem. Sci. 2012, 3, 327; (f) J. Li, Y. Cai, W. Chen, X. Liu, L. Lin, X. Feng, J. Org. Chem. 2012, 77, 9148; (g) X. Gu, Y. Zhang, Z.-J. Xu, C.-M. Che, Chem. Commun. 2014, 50, 7870.

5 (a) X. Dou, Y. Lu, Org. Biomol. Chem. 2013, 11, 5217; (b) T. Wang, D. L. Hoon, Y. Lu, Chem. Commun. 2015, 51, 10186; (c) Y. S. Kim, S. J. Kwon, D. Y. Kim, Bull. Korean Chem. Soc. 2015, 36, 1512; (d) K. Balaraman, R. Ding, C. Wolf, Adv. Synth. Catal. 2017, 359, 4165 6 K. Balaraman, C. Wolf, Angew. Chem., Int. Ed. 2017, 56, 1390.

7 C. Han, E. H. Kim, D. A. Colby, J. Am. Chem. Soc. 2011, 133, 5802.

8 For reviews, see: (a) H. Mei, C. Xie, J. L. Aceña, V. A. Soloshonok, G.-V. Röschenthaler, J. Han, Eur. J. Org. Chem. 2015, 6401; (b) L. Zhang, W. Zhang, W. Sha, H. Mei, J. Han, V. A. Soloshonok, J. Fluorine Chem. 2017, 198, 2.

9 (a) C. Xie, L. Zhang, W. Sha, V. A. Soloshonok, J. Han, Y. Pan, Org. Lett. 2016, 18, 3270; (b) C. Xie, L. Zhang, H. Mei, J. Han, W. A. Soloshonok, Y. Pan, ChemistrySelect 2016, 1, 4435; (c) C. Xi, W. Sha, Y. Zhu, J. Han, V. A. Soloshonok, Y. Pan, RSC Adv. 2017, 7, 5679.

10 Y. Zhu, H. Mei, J. Han, V. A. Soloshonok, J. Zhou, Y. Pan, J. Org. Chem. 2017, 82, 13663.

11 For a review, see: A. Ortega-Martínez, C. Molina, C. MorenoCabrerizo, J. M. Sansano, C. Nájera, Eur. J. Org. Chem. 2018, 2394.

12 (a) A. J. Grenning, J. A. Tunge, Angew. Chem., Int. Ed. 2011, 50, 1688; (b) A. J. Grenning, J. A. Tunge, J. Am. Chem. Soc. 2011, 133, 14785; (c) A. J. Grenning, C. K. Van Allen, T. Maji, S. B. Lang, J. A. Tunge, J. Org. Chem. 2013, 78, 7281; (d) N. Kumar, M. K. Das, S. Ghosh, A. Bisai, Chem. Commun. 2017, 53, 2170. 
13 (a) A. Ortega-Martínez, C. Molina, C. Moreno-Cabrerizo, J. M. Sansano, C. Nájera, Synthesis 2017, 49, 5203; (b) A. OrtegaMartínez, C. Molina, C.Moreno-Cabrerizo, J. M. Sansano, C. Nájera, An. Acad. Bras. Cienc. 2018, 90, 1089.

14 A. Ortega-Martínez, R. de Lorenzo, J. M. Sansano, C. Nájera, Tetrahedron 2018, 74, 253.

15 For Lewis acid catalyzed $\alpha$-halogenation of 1,3-dicabonyl compounds, see: (a) D. Yang, Y.-L. Yan, B. Lui, J. Org. Chem. 2002, 67, 7429; (b) Z.-J. Wu, H.-C. Xu Angew. Chem. Int. Ed. 2017, 56, 4734. 